\title{
A new single step process for synthesis and growth of $\mathrm{ZnGeP}_{2}$ crystal
}

\author{
T.Y. Wang ${ }^{\text {a }}$, R. Sivakumar ${ }^{\text {a }}$, D.K. Rai ${ }^{\text {a,b }}$, W.T. Hsu ${ }^{\text {a }}$, C.W. Lan ${ }^{\text {acc,* }}$ \\ ${ }^{a}$ Department of Chemical Engineering, National Taiwan University, Roosevelt Road, Taipei 10617, Taiwan \\ ${ }^{\mathrm{b}}$ Department of Physics and Materials Science and Engineering, Jaypee Institute of Information Technology University, Noida 201307, India \\ ${ }^{\mathrm{c}}$ Photovoltaics Technology Center, Industrial Technology Research Institute, Hsin-Chu, Taiwan \\ Received 11 December 2007; accepted 28 December 2007
}

\begin{abstract}
A new one-step process for synthesis and growth of zinc-germanium-phosphide, $\mathrm{ZnGeP}_{2}(\mathrm{ZGP})$, is reported for the first time herein using a three-zone resistance furnace by the horizontal gradient freeze technique. A safe and proper temperature scheme has been obtained for both synthesis and growth of ZGP crystals via the melt growth route from $\mathrm{Zn}$, Ge and P powder. The prepared material has been investigated using powder X-ray diffraction which shows the correct ZGP tetragonal phase. EPMA results are also obtained to estimate the compositional homogeneity of the grown crystal.
\end{abstract}

(C) 2008 Published by Elsevier B.V. on behalf of Taiwan Institute of Chemical Engineers.

PACS : 78.55.Hx; 78.30.Am; 81.10.-h; 87.64.Bx; 61.10.-i

Keywords: Inorganic materials; Semiconductors; Crystal growth; Nonlinear optical crystals

\section{Introduction}

Zinc-germanium-phosphide, $\mathrm{ZnGeP}_{2}$ (ZGP), is a semiconducting material of II-IV- $\mathrm{V}_{2}$ group with band gap of about $2.1 \mathrm{eV}$. It has a cubic zinc blende type structure with slightly shifted atomic positions with respect to those of the zinc blende structure of space group $\mathrm{F} \overline{4} 3 \mathrm{~m}$, leading to a tetragonal structure of space group İ̄2d (Kistiah and Murthy, 1984; Shay and Wernick, 1975). ZGP is one of most promising nonlinear optical materials with a large nonlinear optical coefficient $\left(d_{36}=75 \mathrm{pm} / \mathrm{V}\right)$ and a large birefringence (Boyd et al., 1972). These crystals significantly enhance the laser performance by making possible the shifting of wavelength of various laser sources into the mid-infrared $(\sim 2-8 \mu \mathrm{m})$ of the spectrum via second harmonic generation (SHG) and optical parametric oscillation (OPO). However, the application of ZGP has been hindered because of various difficulties in synthesis and growth of single crystals namely, high vapor pressure produced by phosphorous, formation of undesired stable binary compounds like $\mathrm{ZnP}_{2}\left(T_{\mathrm{m}}=1040^{\circ} \mathrm{C}\right)$ and $\mathrm{ZnP}_{3}\left(T_{\mathrm{m}}=1193{ }^{\circ} \mathrm{C}\right)$, zinc diffusion towards the cold junction, cracking and growth

\footnotetext{
* Corresponding author. Tel.: +886 2363 3917; fax: +886 23633917 .

E-mail address: cwlan@ntu.edu.tw (C.W. Lan).
}

of multi-crystals, poor control of stoichiometry, and structural inhomogeneity.

Innumerable amount of work has been done (Bliss et al., 1994; Buehler and Wernick, 1971; Gentile and Stafsudd, 1974; Masumoto et al., 1966; Schunemann and Pollak, 1998; Verozubova et al., 1997, 2000, 2002) and a considerable success has been achieved in understanding of the problems associated with synthesis and growth. Verozubova et al. (1997) have addressed the problem of inappropriate yield, zinc diffusion towards cold zone and also formation of thermally stable binary phases by using two-temperature technique for synthesis. They have been able to optimize a standard temperature scheme for synthesis to accomplish the above. They have studied the growth of crystal using the vertical Bridgman and gradient freezing techniques and discussed the effects that may cause polycrystallinity and physical properties inhomogeneity in ZGP. Schunemann and Pollak (1997) have invented a method for growing large, single and crack free crystals. The method contains two steps-one for synthesis of compound material from the constituents zinc $(\mathrm{Zn})$, germanium $(\mathrm{Ge})$ and phosphorous (P) and the other for forming the crystal. They used horizontal gradient freeze (HGF) technique for seeded growth of ZGP crystal from pre-synthesized polycrystalline ZGP using gold coated transparent furnace. The transparent furnace offers opportunity to see and maneuver the process of melting and subsequent growth of the crystal. The method has been used 
successfully for the growth of single crystals weighing up to $500 \mathrm{~g}$ for the first time. However, involving a two-step process for synthesis and growth is laborious and a simplified process may be more useful for industrial application.

In this paper, we report a new one-step process for synthesis and growth of ZGP crystal as a convenient and economically viable possibility. In order to estimate potentiality of the proposed method, properties of the grown crystals have also been studied and reported in the paper.

\section{Experimental}

The high purity (99.9999\%) powders of constituent elements $\mathrm{Zn}, \mathrm{Ge}$ and $\mathrm{P}$ were taken in molar ratio of 1:1:2. In order to compensate the possible loss of zinc and phosphorous during synthesis, 0.005 mole of zinc and 0.01 mole of phosphorous were taken in excess of their stoichiometric amount. A specially designed pyrolytic boron nitride (PBN) coated graphite crucible was taken for synthesis and growth. The idea was, first of all, to create a suitable temperature condition such that reaction between the constituents takes place within the crucible with minimum loss of materials. To accomplish this, the mixture of $\mathrm{Zn}$ and Ge powder was filled in the crucible. Then, the filled crucible and the third constituent phosphorous were placed separately in a quartz ampoule. To avoid presence of oxygen inside the ampoule, all steps were performed in nitrogen atmosphere. The filled ampoule was then purged with argon as a final attempt to avoid the presence of oxygen. The purged ampoule was then evacuated and sealed for further experiment. A horizontal three-zone resistance furnace was used for melt growth of the ZGP crystal. The sealed ampoule containing constituent materials was placed into the furnace in such a way that crucible falls in the hot zone and phosphorous falls in the cold zone. For synthesis of the material, temperature scheme similar to as specified by Verozubova et al. (1997) has been used:

(i) The hot and cold zones of the furnace were heated simultaneously up to $1000{ }^{\circ} \mathrm{C}$ and $520^{\circ} \mathrm{C}$, respectively. This temperature scheme minimizes the diffusion of $\mathrm{Zn}$ vapor towards the cold zone.

(ii) Material was kept for soaking at this temperature for a period of $2-3 \mathrm{~h}$ in order to ensure the complete sublimation of phosphorous and reaction between the constituents.

(iii) The hot zone temperature was further raised up to $1050{ }^{\circ} \mathrm{C}$ and cold zone up to $1060{ }^{\circ} \mathrm{C}$. The melt was kept for soaking at this temperature for $10-15 \mathrm{~h}$ in order to ensure the homogeneous melt formation.

The growth of the crystal was performed by cooling the melt at the rate of $1.2{ }^{\circ} \mathrm{C} / \mathrm{h}$ down to $1000{ }^{\circ} \mathrm{C}$ well below the melting point $1027{ }^{\circ} \mathrm{C}$ of ZGP. Further cooling of the material was done at the rate of $20.4^{\circ} \mathrm{C} / \mathrm{h}$ down to the room temperature.

The phase analysis of the grown ZGP crystal was carried out by powder X-ray diffraction (XRD) using X-ray diffractometer (MAC Science, MO3XHF). The compositional analysis in different parts of the ingot was carried out by electron probe micro analyzer (EPMA) (JEOL, JXA-8200).

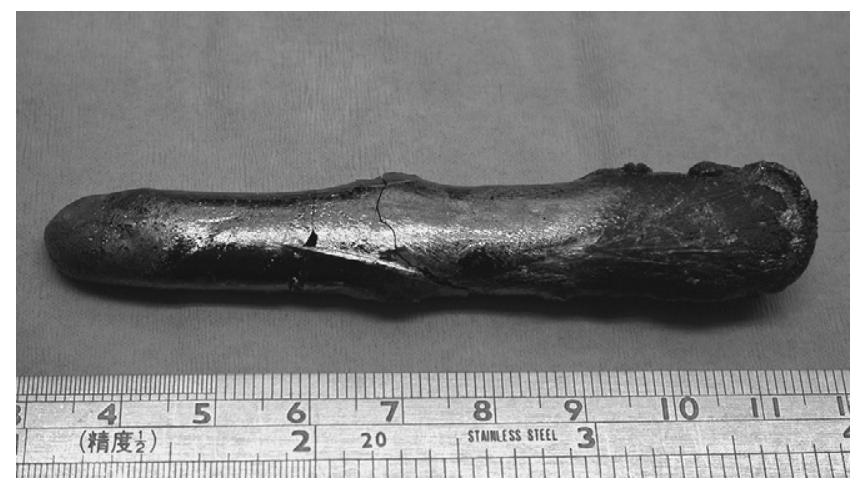

Fig. 1. Photograph of grown ZGP crystal.

\section{Results and discussion}

Melt crystallization following the above temperature scheme resulted into a polycrystalline ingot. In a typical experiment an ingot of about $8 \mathrm{~cm}$ length and $6 \mathrm{~mm}$ thickness weighing $28.61 \mathrm{~g}$ with good surface morphology was obtained as shown in Fig. 1. A weight loss of about $6.5 \%$ was observed in the final compound. The weight loss may be attributed to the possible formation of binary compounds like $\mathrm{ZnP}_{2}$ or $\mathrm{ZnP}_{3}$ outside the crucible. The obtained ingot is also found to have crack which is because of the polycrystalline nature of the ingot.

The powder X-ray diffraction was recorded for the powders scraped from different parts of the grown crystal. The diffraction pattern and assignment of different peaks are shown in Fig. 2. The comparison of the peaks with that of standard pattern of ZGP shows the presence of tetragonal phase in all parts of the crystal. The lattice parameters of the tetragonal phase was calculated to be $a=b=5.4528 \AA$ and $c=10.6656 \AA$ which is consistent with the standard data (JCPDS card no. 33-1471).

In order to measure composition of constituents at different positions in the grown crystal, EPMA was carried out. The comparative composition variation of the constituents is shown in Fig. 3. According to the figure, all the elements $\mathrm{Zn}, \mathrm{Ge}$ and $\mathrm{P}$ are observed to be nearly uniform throughout the length of the crystal. Further, the ratio of the three constituents is also found

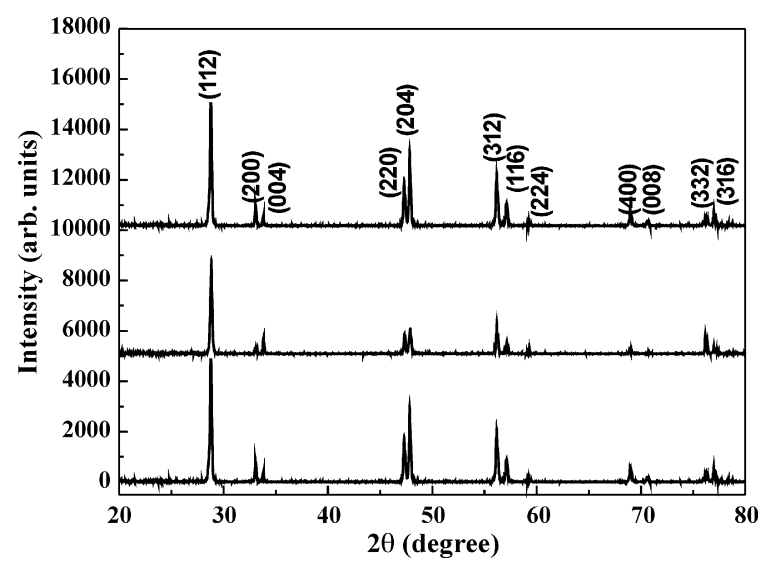

Fig. 2. X-ray diffraction patterns of different parts of ZGP crystal. 


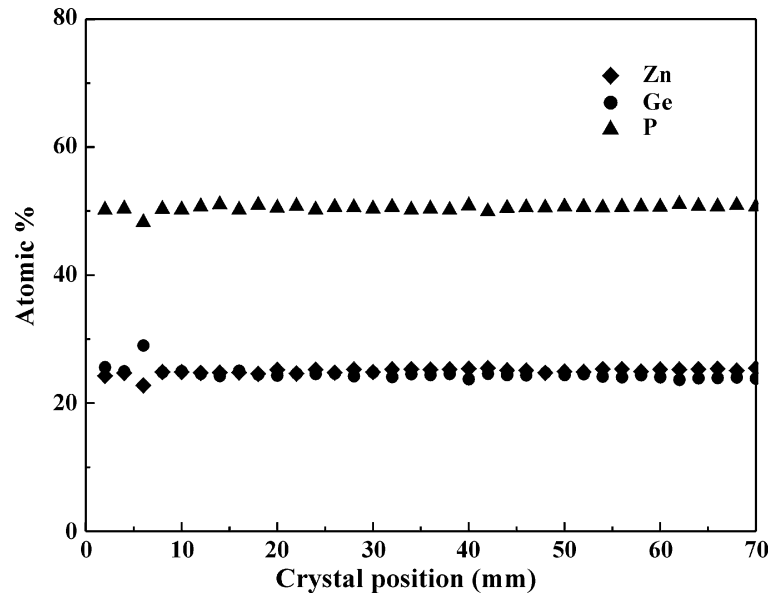

Fig. 3. EPMA result of $\mathrm{Zn}, \mathrm{Ge}$ and $\mathrm{P}$ in the crystal.

to be close to the desired stoichiometry of zinc, germanium and phosphorous, i.e. 1:1:2.

\section{Conclusions}

A new feasible approach of one-step synthesis and growth of ZGP has been proposed. Using this approach, ZGP crystal has been grown successfully. The grown crystal has been found to have tetragonal structure with $a=b=5.4528 \AA$ and $c=10.6656 \AA$, which are close to the standard values of ZGP crystal. The crystal is found to possess structural uniformity, and also the composition close to the stoichiometry throughout the bulk of the crystal.

\section{Acknowledgements}

This work was supported by research grant NSC 96-2221-E002-095 received from National Science Council (NSC),
Taiwan. One of us (DKR) also wishes to acknowledge the financial support received from NSC through the fellowship grant NSC 96-2811-E-002-015.

\section{References}

Bliss, D. F., M. Harris, J. Horrigan, W. M. Higgins, A. F. Armington, and J. A. Adamski, "Synthesis and Growth Processes for Zinc Germanium Diphosphide," Cryst. Growth J., 137, 145 (1994).

Boyd, G. D., H. M. Kasper, J. H. McFee, and F. G. Storz, "Linear and Nonlinear Optical Properties of Some Ternary Selenides," IEEE J. Quant. Electron., 8, 900 (1972).

Buehler, E. and J. H. Wernick, "Concerning Growth of Single Crystals of the II-IV-V Diamond-like Compounds $\mathrm{ZnSiP}_{2}, \mathrm{CdSiP}_{2}, \mathrm{ZnGeP}_{2}$, and $\mathrm{CdSnP}_{2}$ and Standard Enthalpies of Formation for $\mathrm{ZnSiP}_{2}$ and $\mathrm{CdSiP}_{2}, "$ Cryst. Growth J., 8, 324 (1971).

Gentile, A. L. and O. M. Stafsudd, "Crystal Growth of $\mathrm{A}^{\mathrm{II}} \mathrm{B}^{\mathrm{IV}} \mathrm{C}_{2}{ }^{\mathrm{V}}$ Chalcopyrites," Mater. Res. Bull., 9, 105 (1974).

Kistiah, P. and K. S. Murthy, "Temperature Dependence of Tetragonal Distortion in $\mathrm{A}^{\mathrm{II}} \mathrm{B}^{\mathrm{IV}} \mathrm{C}_{2}{ }^{\mathrm{V}}$ Chalcopyrite Semiconductors," Mater. Sci. Lett. J., 3, 767 (1984).

Masumoto, K., S. Isomura, and W. Goto, "The Preparation and Properties of $\mathrm{ZnSiAs}_{2}, \mathrm{ZnGeP}_{2}$ and $\mathrm{CdGeP}_{2}$ Semiconducting Compounds," Phys. Chem. Solids J., 27, 1939 (1966).

Schunemann, P. G. and T. M. Pollak, "Methods for Growing Crystals," U.S. Patent 5, 611, 856 (1997)

Schunemann, P. G. and T. M. Pollak, "Ultralow Gradient HGF-Grown $\mathrm{ZnGeP}_{2}$ and CdGeAs ${ }_{2}$ and Their Optical Properties," MRS Bull., 23, 23 (1998).

Shay, J. L. and J. H. Wernick, Ternary Chalcopyrite Semiconductors: Growth, Electronic Properties, and Applications, Pergamon Press, New York, U.S.A., p. 3 (1975).

Verozubova, G. A., A. I. Gribenyukov, V. V. Korotkova, and M. P. Ruzaikin, "ZnGeP 2 Synthesis and Growth from Melt," Mater. Sci. Eng., B48, 191 (1997)

Verozubova, G. A., A. I. Gribenyukov, V. V. Korotkova, O. Semchinova, and D. Uffmann, "Synthesis and Growth of $\mathrm{ZnGeP}_{2}$ Crystals for Nonlinear Optical Applications," Cryst. Growth J., 213, 334 (2000).

Verozubova, G. A., A. I. Gribenyukov, V. V. Korotkova, A. W. Vere, and C. J. Flynn, " $\mathrm{ZnGeP}{ }_{2}$ Growth: Melt Non-Stoichiometry and Defect Substructure," Cryst. Growth J., 237-239, 2000 (2002). 